\title{
Characterization of Electromagnetic Wave Absorbers with Broadside SRR Method on C-Band
}

\author{
Dwi Banyu Prawito ${ }^{1}$, Rasheed Abdurrahman Mulyadi² ${ }^{2}$ Budi Syihabuddin ${ }^{3}$, Levy Olivia Nur ${ }^{4}$
}

\begin{abstract}
Electromagnetic waves absorbers are materials that can dampen the energy presenting in electromagnetic waves. Electromagnetic wave absorbers can be utilized to reduce interferences on wireless communication devices so as not to quickly damaged, to serve as a layer in a free-reflections room, and to reduce cross section radar of an object detected in radar tracking applications. In this paper, a discussion on the use of the Broadside shape using the Split Ring Resonator (SRR) method as an electromagnetic wave absorber and its characteristics on the $C$ Band is carried out. The broadside shape was derived from the initial square shape developed into a square resonator and then given a gap on its resonance end. Results showed that the broadside SRR shape could be used as an electromagnetic wave absorber on C-Band, precisely at a frequency of $6.41 \mathrm{GHz}$, with an absorption rate of $99.99 \%$ and bandwidth of $0.077 \mathrm{GHz}$, with a dimension of $7 \mathrm{~mm}$. From the experiment results, it could also be seen that the modification in the gap length variable in the broadside SRR shape was the most influencing change in the resonant frequency value and the produced bandwidth.
\end{abstract}

Keywords-Electromagnetic Wave Absorbers, SRR, Broadside SRR, C-Band.

\section{INTRODUCTION}

An electromagnetic wave absorber is a material that is able to dampen the energy in electromagnetic waves by reducing reflected waves. Some of electromagnetic wave absorbers applications are as a protection from unwanted electromagnetic waves, as materials to create a free-reflection room, and for radar tracking applications. Electromagnetic wave absorber materials can be used to reduce radar cross-section (RCS) of a detected object [1]-[4].

Electromagnetic wave absorber can be created through several methods, including through Artificial Magnetic Conductor (AMC) and Frequency Selective Surface (FSS) [2][3]. AMC is a material that has properties similar to Perfect Magnetic Conductor (PMC) in terms of reflection characteristics, which can reflect electromagnetic waves without changing the reflection phase [2], while FSS is an absorber type that utilizes electrical resonance [3].

Based on the characteristics of surface impedance, absorbers of electromagnetic waves can be divided into two, namely Lossy and Lossless electromagnetic wave absorbers. A lossy electromagnetic wave absorber is an absorber that has a thin thickness and has a wide band because of the high impedance

\footnotetext{
1,2 Student, School of Electrical Engineering, Telkom University, Bandung, INDONESIA, 40257. (\{banyuprawito, rasheed\}@student.telkomuniversity.ac.id)

${ }^{3,4}$ Lecturer, School of Electrical Engineering, Telkom University, Bandung, INDONESIA, 40257. (\{budisyihab, levyolivia\}@telkomuniversity.ac.id)
}

value. However, Lossy type absorbers are difficult to produce because it is difficult to properly obtain high surface impedance. In contrast, a lossless electromagnetic wave absorber is an absorber consisting of an easily-produced metal surface but it has a narrow bandwidth [5].

Materials that have a surface impedance value equal to the air impedance value can completely absorb electromagnetic waves [1]. One of the methods used to adjust the surface impedance value is to adjust the conductor's shape and dimensions. Some conductor shapes can function as resonators [6]. In several previous studies, the use of several geometric shapes as electromagnetic wave absorbers by using FR-4 as a substrate material and it operates on C-Band has been studied. Various geometric shapes that had been studied produced good absorption levels [4], [7]-[10].

In the research that had been done, the use of two hexagonal rings shapes generated an absorber with a resonance frequency of $6.41 \mathrm{GHz}$ which had an absorption rate of $98.5 \%$ and had a dimension of one cell unit of $12 \mathrm{~mm}$ [4]. Then, based on [7], an absorber with two concentric circular rings shape had a resonance frequency of $6.13 \mathrm{GHz}$ with an absorption rate of $99.83 \%$ and had a dimension of one cell unit of $23 \mathrm{~mm}$. Absorbers with rectangular rings with gaps shape could work at a resonance frequency of $7 \mathrm{GHz}$ with absorption rates reaching $95.1 \%$ and had a dimension of one cell unit of $18 \mathrm{~mm}$ [8]. Furthermore, based on [9], the use of asymmetric triangle split-ring resonators produced absorbers with a resonance frequency of $7.95 \mathrm{GHz}$ which had an absorption rate of $98.9 \%$ and had a dimension of $8 \mathrm{~mm}$. And in [10], absorbers with a double annular slot ring resonator shape could work at a resonance frequency of $5.8 \mathrm{GHz}$ with absorption rates reaching $97.75 \%$ and it had dimensions of $13 \mathrm{~mm}$.

In this paper, the effects of different shapes and dimensions of electromagnetic waves absorbers were analysed to observe the absorption quality in C-Band. C-Band is part of the electromagnetic wave spectrum in the microwave range with a frequency of 4 to $8 \mathrm{GHz}$ [11]. In the C-Band range there are several technologies, such as Fixed Satellite Service [12], WiFi [13], and some weather radar systems [14]. Then a characterization of electromagnetic wave absorber which had the best dimensions was carried out to determine the effect of modifications in some of the constituent variables. The material used for patches and ground planes in this electromagnetic wave absorber were copper. In addition, the utilized substrate material was FR-4 with a thickness of $1 \mathrm{~mm}$.

\section{Electromagnetic Wave Absorber Design}

In this paper, the electromagnetic wave absorber was designed with an initial square shape. After that, simulations and optimizations were carried out to obtain the optimal 

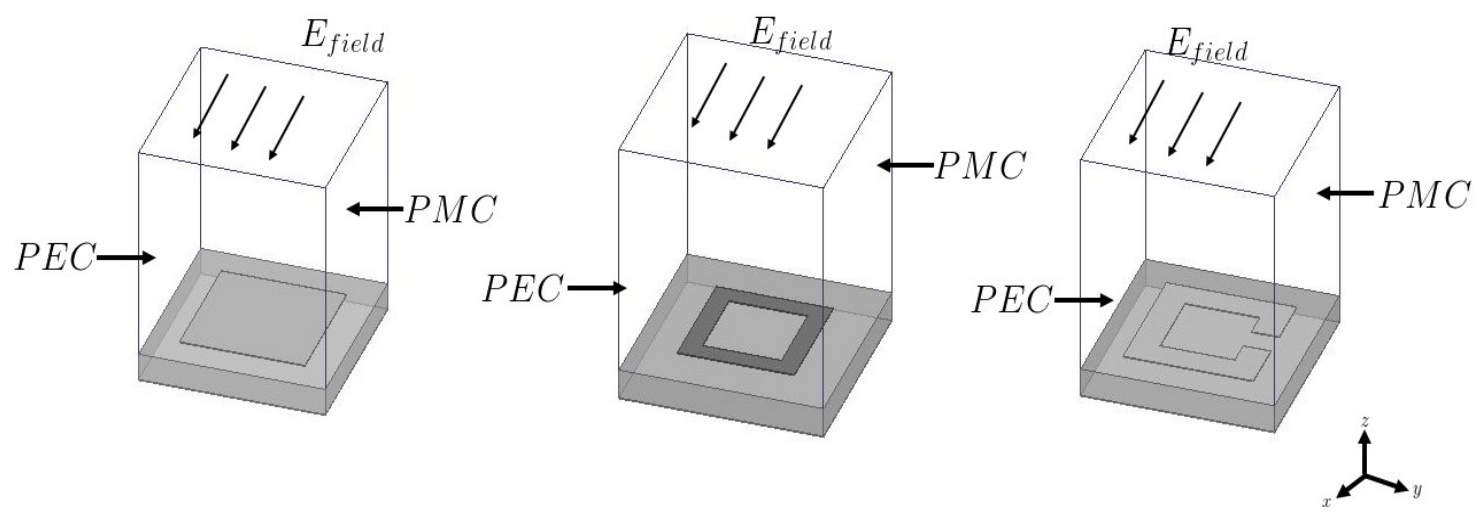

Fig. 1 Cell-unit boundary.

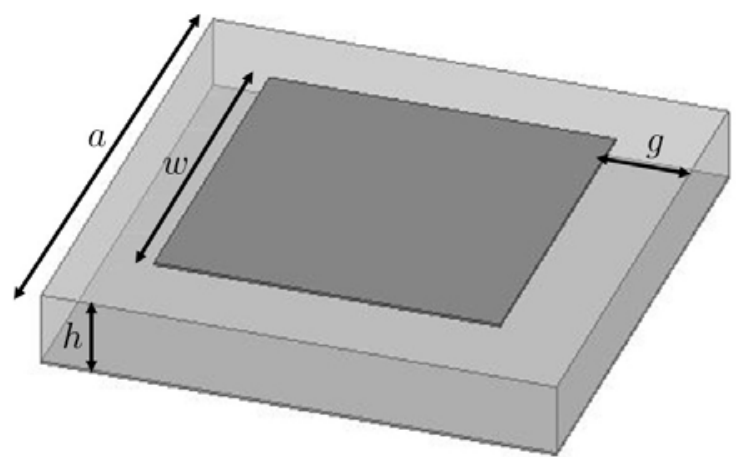

Fig. 2 A square electromagnetic wave absorber design.

absorber dimensions at the resonant frequency. From these results, a square resonator and broadside Split Ring Resonator (SRR) shaped electromagnetic wave absorber design were created. The SRR method was utilized because it could produce strong magnetic couplings to be applied to electromagnetic fields which were not normally found in conventional materials. SRR could also produce smaller electrical effects when responding to resonant electromagnetic waves [6].

A boundary was employed at the simulation stage in order to be able to obtain accurate results. The boundary was utilized to create an unlimited array cell unit condition. Boundary was arranged as Perfect Electric Conductor (PEC) and Perfect Magnetic Conductor (PMC) on the side of the wall and parallel to the electric field as shown in Fig. 1 [15].

The initial design of electromagnetic wave absorbers used a square shape, as shown in Fig. 2. A square electromagnetic wave absorber dimension was obtained from the AMC cell equation approach by observing the working frequency values [15]. Equations (1) through (7) are square AMC cell unit equations [15].

$$
f_{0}=\frac{1}{2 \pi} \sqrt{\frac{\left(X_{1}\right)+\sqrt{X_{1}{ }^{2}-4 X_{2}}}{2 X_{2}}}
$$

with

$$
\begin{aligned}
& X_{1}=L_{s r} C_{s r}+L_{s h} C_{s h}+L_{s r} C_{s h} \\
& X_{2}=L_{s r} L_{s h} C_{s r} C_{s h}
\end{aligned}
$$

$$
\begin{aligned}
& C_{s r}=\frac{2 \varepsilon}{\pi \mathrm{w}} \cosh ^{-1}\left(\frac{a}{g}\right) \\
& L_{s r}=\frac{\pi \mathrm{w} \mu}{2 \cosh h^{-1}\left(\frac{a}{g}\right)} \\
& C_{s h}=\frac{\varepsilon w^{2}}{t} \\
& L_{s h}=\mu t
\end{aligned}
$$

for

$C_{s r}=$ series capacitance

$L_{s r}=$ series inductance

$C_{s h}=$ shunt capacitance

$L_{s h}=$ shunt inductance.

In calculating the dimensions of a square electromagnetic wave absorber, there were several variables which values were predetermined, namely the permittivity values $(\varepsilon)$ and the permeability values $(\mu)$, by using (8) and (9).

$$
\begin{aligned}
& \varepsilon=\varepsilon_{o} \cdot \varepsilon_{1} \\
& \mu=\mu_{o} \cdot \mu_{1}
\end{aligned}
$$

with $\varepsilon_{o}=8.854 \times 10^{-12} \mathrm{~F} / \mathrm{m}$ and $\varepsilon_{1}=4.4 \mathrm{~F} / \mathrm{m} \quad$ (a multiplication between the copper permittivity value of $1 \mathrm{~F} / \mathrm{m}$ and the FR4 permittivity value of $4.4 \mathrm{~F} / \mathrm{m}$ ), so that the value of $\varepsilon$ was $3.896 \times 10^{-11} \mathrm{~F} / \mathrm{m}$. Meanwhile, $\mu_{\mathrm{o}}=4 \pi \times 10^{-7} \mathrm{H} /$ $\mathrm{m}$ and $\mu_{1}=1.0000004 \mathrm{H} / \mathrm{m}$ (a multiplication between copper permeability value of $1 \mathrm{H} / \mathrm{m}$ and air permeability of 1.0000004 $\mathrm{H} / \mathrm{m})$, so that the $\mu$ was $1.257 \times 10^{-6} \mathrm{H} / \mathrm{m}$.

The results of a square electromagnetic wave absorber dimension approach were determined by trying to input the values of $a, w$ and $g$ into (1) to (7) until a resonance frequency value was obtained. Dimension calculation results to produce 6.41 GHz oscillation frequency are shown in Table I.

From the dimensions of a square electromagnetic wave absorber, then the square resonator absorber design was generated as shown in Fig. 3. A square resonator was formed from a square that was cut in the middle using a square with a side that was as long as $w_{\text {pot }}$.

Afterward, from the design of a full-resonator-shaped electromagnetic wave absorber, a broadside SRR electromagnetic wave absorber could be designed as shown in 
TABLE I

A Square Electromagnetic Wave Absorber Initial Design DIMENSION

\begin{tabular}{|c|c|c|}
\hline Variable & Description & Dimension (mm) \\
\hline$h$ & Substrate thickness & 1.00 \\
\hline$a$ & Ground plane length & 35.50 \\
\hline$w$ & Patch length & 35.00 \\
\hline$g$ & Gap & 0.50 \\
\hline
\end{tabular}

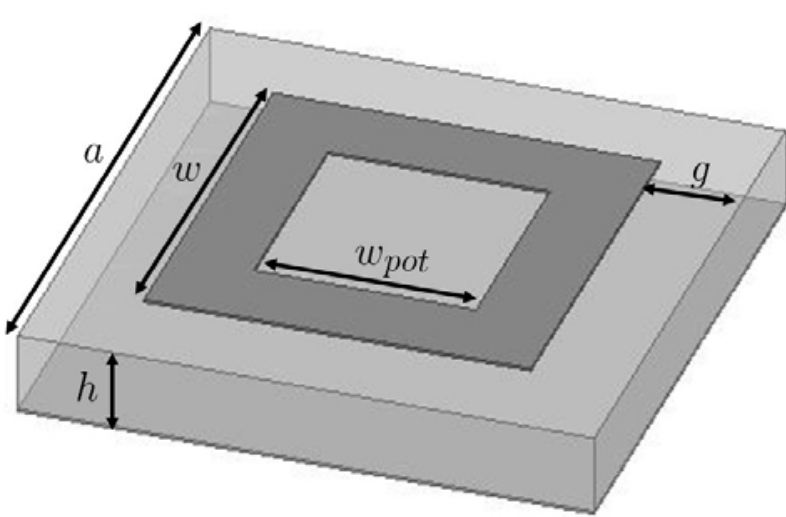

Fig. 3 A square resonator electromagnetic wave absorber design.

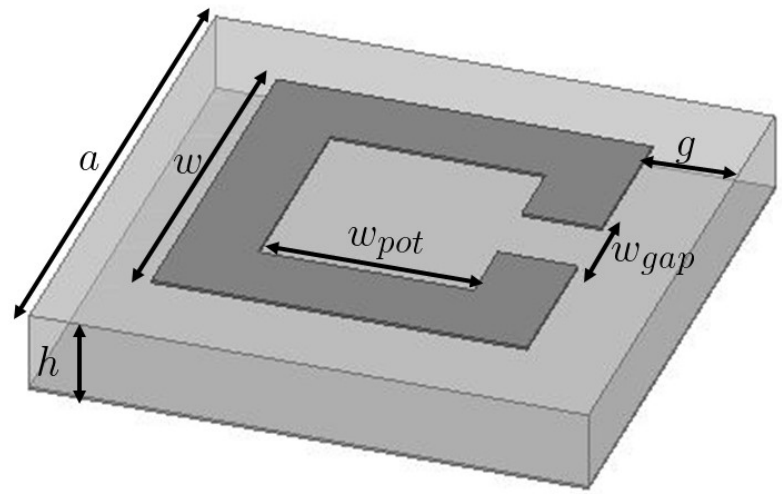

Fig. 4 An SRR-broadside-shaped electromagnetic wave absorber design.

Fig. 4. The broadside SRR shape was constructed from a square resonator added with gaps at the end of the resonator as far as the $w_{\text {gap }}$.

After the electromagnetic wave absorber was designed, then it was simulated with the assistance of a software. Then, the next step was to do the optimization to obtain the optimal absorber dimension at the resonance frequency of $6.41 \mathrm{GHz}$. Optimization was carried out with trial and error method. Trial and error method was carried out by changing the variable values existing in the initial design until it achieved the desired results. The optimal dimensions obtained for the square electromagnetic wave absorber are shown in Table II, for the square resonator electromagnetic wave absorber in Table III, and for broadside SRR shaped electromagnetic wave absorber in Table IV.

\section{SimUlation RESUlts AND Discussions}

This section analyses two things, namely the absorption rate of each electromagnetic wave absorber shape and the
TABLE II

Optimized DESIGN Dimension OF SQUARE ELECTROMAGNETIC WAVE ABSORBER

\begin{tabular}{|c|c|c|}
\hline \multirow{2}{*}{ Variable } & \multicolumn{2}{|c|}{ Square Shape } \\
\cline { 2 - 3 } & Description & Dimension (mm) \\
\hline$h$ & Substrate thickness & 1.00 \\
\hline$a$ & Ground plane length & 17.87 \\
\hline$w$ & Patch length & 9.76 \\
\hline$g$ & Gap & 9.11 \\
\hline
\end{tabular}

TABLE III

Optimized DESIGN DiMENSION OF SQUARE RESONATOR ELECTROMAGNETIC WAVE ABSORBER

\begin{tabular}{|c|c|c|}
\hline \multirow{2}{*}{ Variable } & \multicolumn{2}{|c|}{ Square Resonator } \\
\cline { 2 - 3 } & Description & Dimension $(\mathbf{m m})$ \\
\hline$h$ & Substrate thickness & 1.00 \\
\hline$a$ & Ground plane length & 16.25 \\
\hline$w$ & Patch length & 8.06 \\
\hline$g$ & Gap & 8.19 \\
\hline$w_{\text {pot }}$ & Resonator cut length & 5.80 \\
\hline
\end{tabular}

TABLE IV

OPTIMIZED DESIGN DIMENSION OF SQUARE BROADSIDE SRR ELECTROMAGNETIC WAVE ABSORBER

\begin{tabular}{|c|c|c|}
\hline \multirow{2}{*}{ Variable } & \multicolumn{2}{|c|}{ Broadside SRR } \\
\cline { 2 - 3 } & Description & Dimension (mm) \\
\hline$h$ & Substrate thickness & 1.00 \\
\hline$a$ & Ground plane length & 7.00 \\
\hline$w$ & Patch length & 4.70 \\
\hline$g$ & Gap & 2.30 \\
\hline$w_{\text {pot }}$ & Resonator cut length & 2.70 \\
\hline$w_{\text {gap }}$ & Resonator gap length & 0.90 \\
\hline
\end{tabular}

characteristics of the broadside SRR as an electromagnetic wave absorber based on changes in several variables.

\section{A. Absorption Rates of the Electromagnetic Wave Absorbers}

The absorption rates are reviewed to determine the quality of an electromagnetic wave absorber. The absorption rate of an electromagnetic wave absorber can be reviewed based on the return loss value $\left(S_{11}\right)$ and insertion loss value $\left(S_{21}\right)$ [16]. The insertion loss value in the electromagnetic wave absorber was designed equal to zero because it was designed in a full ground plane shape.

Equation (10) is an equation to find out the absorption rate of an electromagnetic wave absorber. The absorption rate was reviewed as a percentage based on calculation results using (10). The reviewed absorption rate was on C-Band, with the resonance frequency for each electromagnetic wave absorber was of $6.41 \mathrm{GHz}$.

$$
A=1-\left|S_{11}\right|^{2}-\left|S_{21}\right|^{2} .
$$

Fig. 5 shows the absorption rates of a square electromagnetic wave absorber, square resonator, and broadside SRR. The square electromagnetic wave absorber can work well at its resonant frequency with a maximum absorption rate of up to $100 \%$. This electromagnetic wave absorber shape has a bandwidth of $0.169 \mathrm{GHz}$. However, the dimensions of square 


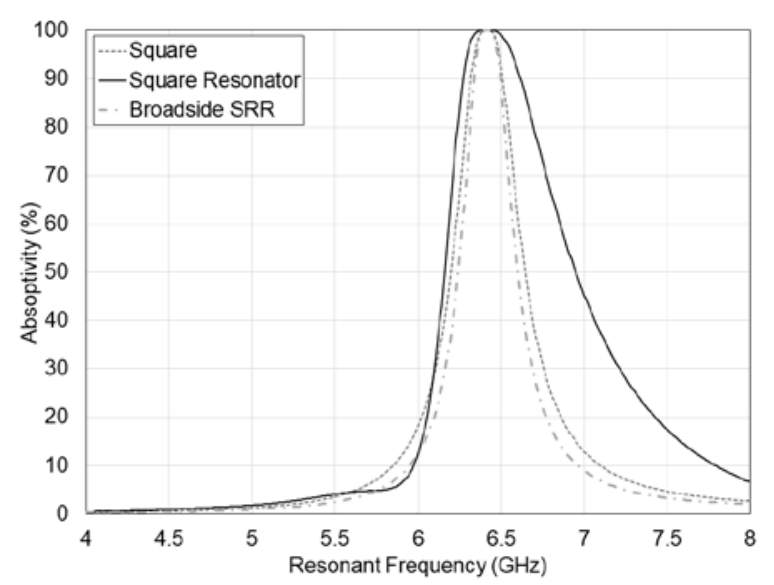

Fig. 5 An absorption rates comparison of the square absorber, square resonator, and broadside SRR.

absorber are still too large, having a patch length of $9.79 \mathrm{~mm}$ and the ground plane side length of $17.84 \mathrm{~mm}$.

Electromagnetic wave absorber with a square resonator has smaller dimensions than a square electromagnetic wave absorber. Optimal dimensions of square resonator absorber are $8.06 \mathrm{~mm}$ for patch side length and $16.25 \mathrm{~mm}$ for ground plane side length with square cut addition in the middle of the path with a side length of $5.8 \mathrm{~mm}$. However, the absorption rate for the square resonator absorber decreases to $99.971 \%$ at its resonant frequency, with a bandwidth of $0.089 \mathrm{GHz}$.

The broadside SRR electromagnetic wave absorber has the lowest dimension compared to the square and square resonator electromagnetic wave absorbers. The optimal dimensions for absorbing electromagnetic waves in the broadside SRR are 4.7 $\mathrm{mm}$ for the patch side length, $7 \mathrm{~mm}$ for the ground plane side length, and 2.7 for the cut edge length. In the broadside SRR absorber a $0.9 \mathrm{~mm}$ long gap was added to the end of the resonator. The absorption rate for the broadside SRR absorber achieves good results on its resonance, which reaches $99.999 \%$. However, this electromagnetic wave absorber shape has the narrowest bandwidth compared to other shapes, which is 0.077 GHz.

\section{B. Broadside SRR Characteristics as an Electromagnetic Wave Absorber}

As discussed in subsection A, the broadside SRR could work well when applied as an electromagnetic waves absorber with absorption rates reaching $99.999 \%$ at a frequency of $6.41 \mathrm{GHz}$, with a bandwidth of $0.077 \mathrm{GHz}$. The advantage of this shape compared to the square and the square resonator shapes is its smaller dimension.

On this sub-section, the broadside SRR characterization is used as an electromagnetic waves absorber. The characterization process was carried out by performing changes to several variables that were used to design the broadside SRR electromagnetic wave absorber. This was carried out to determine the broadside SRR characteristics as an electromagnetic waves absorber when operated on a C-Band. The observed parameters were the changes in resonance frequency and bandwidth magnitude based on the changes in the broadside SRR constituent variables.

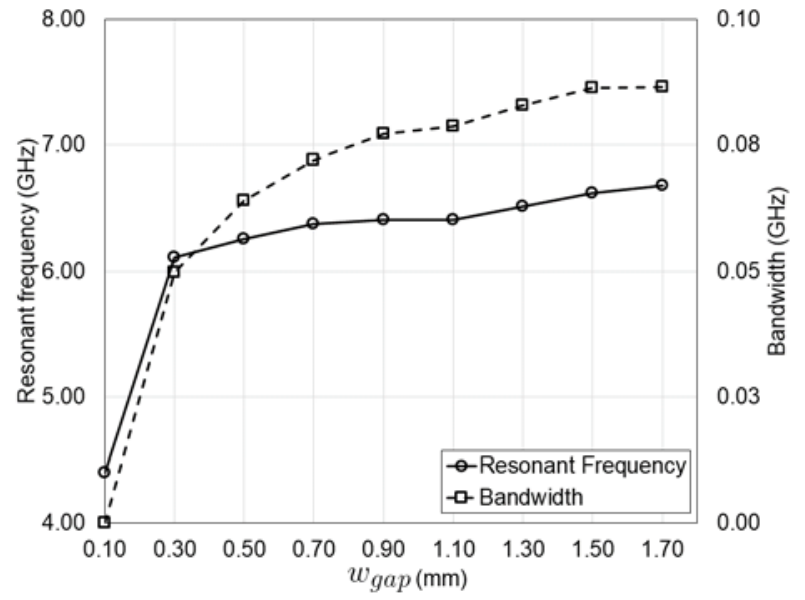

Fig. 6 Resonance frequency and bandwidth values due to changes in gap length.

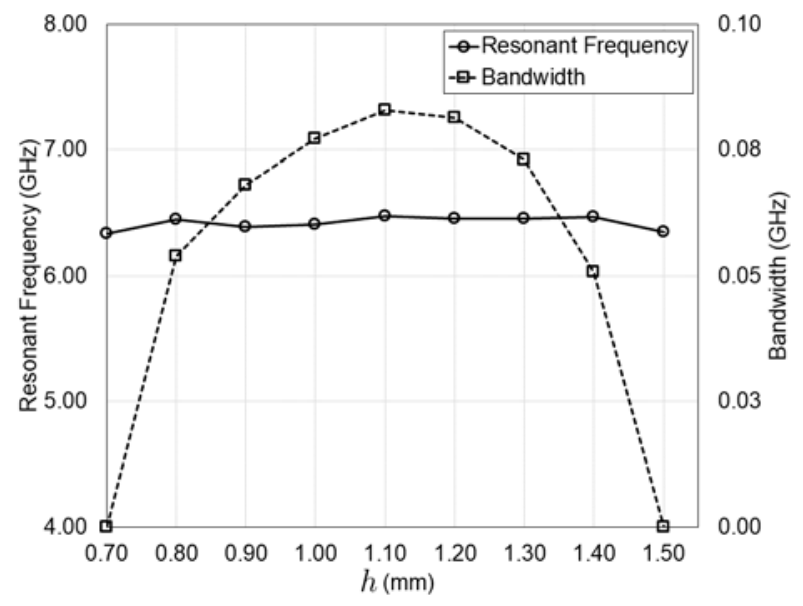

Fig. 7 Resonance frequency and bandwidth values due to changes in substrate thickness.

Fig. 6 shows the effect of changing the gap length on the broadside SRR electromagnetic wave absorber to the resonant frequency value and the bandwidth magnitude. The resonance frequency becomes greater if the gap on the resonator is increased. Of the nine samples taken, the most significant increase in the value of the resonance frequency occurs when the gap length is changed from $0.1 \mathrm{~mm}$ to $0.3 \mathrm{~mm}$, i.e. the resonant frequency changes from $4.4 \mathrm{GHz}$ to $6.11 \mathrm{GHz}$. The greatest resonant frequency value occurs when the gap length is changed to $1.7 \mathrm{~mm}$, with a value reaching $6.68 \mathrm{GHz}$. Changes in gap length also result in changes in bandwidth values. The longer the gap in the electromagnetic wave absorber in the broadside SRR is, the greater the bandwidth is. The most significant change occurred when the gap length was changed from $0.1 \mathrm{~mm}$ to $0.3 \mathrm{~mm}$, which resulted in the value of bandwidth increasing from $0 \mathrm{GHz}$ to $0.049 \mathrm{GHz}$.

Fig. 7 shows the effect of changes in substrate thickness on the broadside SRR electromagnetic wave absorber on the resonant frequency values and the bandwidth magnitude. Changes in substrate thickness do not significantly influence the changes in resonant frequency. From the nine samples taken, the resonant frequency value is relatively stable. The 


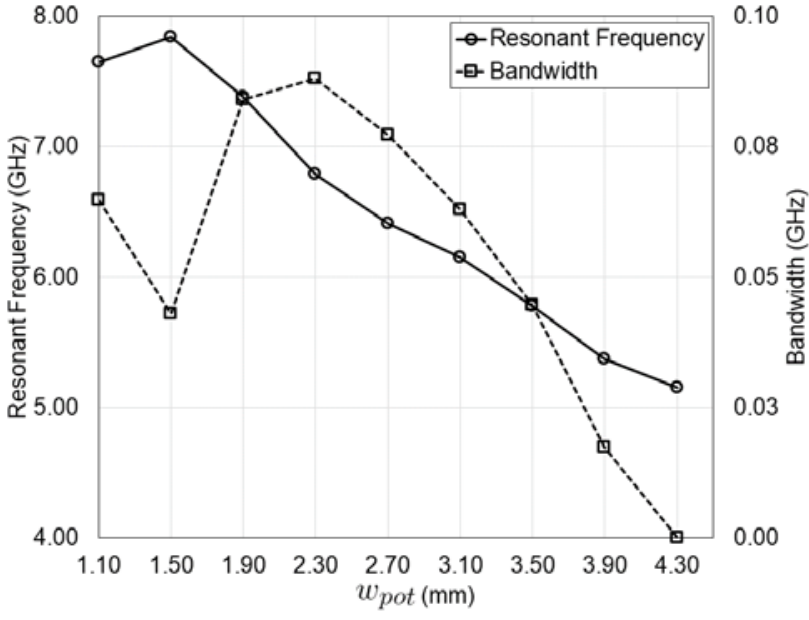

Fig. 8 Values of resonance frequency and bandwidth due to changes in cut side length.

most significant change in the value of the resonance frequency occurs when the thickness of the substrate is increased from 1.4 $\mathrm{mm}$ to $1.5 \mathrm{~mm}$, which results in a decrease in the resonant frequency value, from $6.47 \mathrm{GHz}$ to $6.35 \mathrm{GHz}$. The resonant frequency reaches a maximum value when the thickness of the substrate is $1.1 \mathrm{~mm}$, which is $6.48 \mathrm{GHz}$. Changes in substrate thickness also affect the bandwidth magnitude. When the substrate thickness are of $0.7 \mathrm{~mm}$ and $1.7 \mathrm{~mm}$, the broadside SRR electromagnetic wave absorber has no bandwidth or its bandwidth equals to zero. However, the broadside SRR electromagnetic wave absorber has a bandwidth when the substrate has a thickness of $0.8 \mathrm{~mm}$ to $1.4 \mathrm{~mm}$. The most significant change in bandwidth occurs when the substrate thickness is changed from $1.3 \mathrm{~mm}$ to $1.4 \mathrm{~mm}$, which causes the bandwidth to decrease by $0.023 \mathrm{GHz}$, from $0.073 \mathrm{GHz}$ to 0.5 $\mathrm{GHz}$. The maximum bandwidth is obtained when the substrate has a thickness of $1.1 \mathrm{~mm}$, with a bandwidth of $0.083 \mathrm{GHz}$.

Fig. 8 shows the changes in the resonant frequency values and the bandwidth magnitude due to the effect of changes in the side cut length. The resonance frequency values undergo a significant change due to the modification in the cut edge length. Of the nine samples taken, there is an increase in the resonance frequency value when the cut edge length is changed from $1.1 \mathrm{~mm}$ to $1.5 \mathrm{~mm}$, from $7.65 \mathrm{GHz}$ to $7.84 \mathrm{GHz}$. Then, if the cut side length is increased, the resonant frequency value decreases. The bandwidth magnitude is also affected by the cut edge length. From the nine samples taken, the change in bandwidth values varies considerably. When the cut length is changed from $1.1 \mathrm{~mm}$ to $1.5 \mathrm{~mm}$, the bandwidth decreases by $0.021 \mathrm{GHz}$ and when the cut length is changed from $1.5 \mathrm{~mm}$ to $2.3 \mathrm{~mm}$, the bandwidth increases and reaches its maximum point, which is $0.088 \mathrm{GHz}$. Then, if the cut side length is amplified to more than $2.3 \mathrm{GHz}$, the bandwidth will decrease.

Fig. 9 shows the effect of changes in the resonator side length to changes in the resonant frequency values and the bandwidth magnitude. Modification in the resonator side length significantly influences the change in the resonance frequency values and bandwidth. From the nine samples taken, the resonant frequency value decreases if the resonator side length

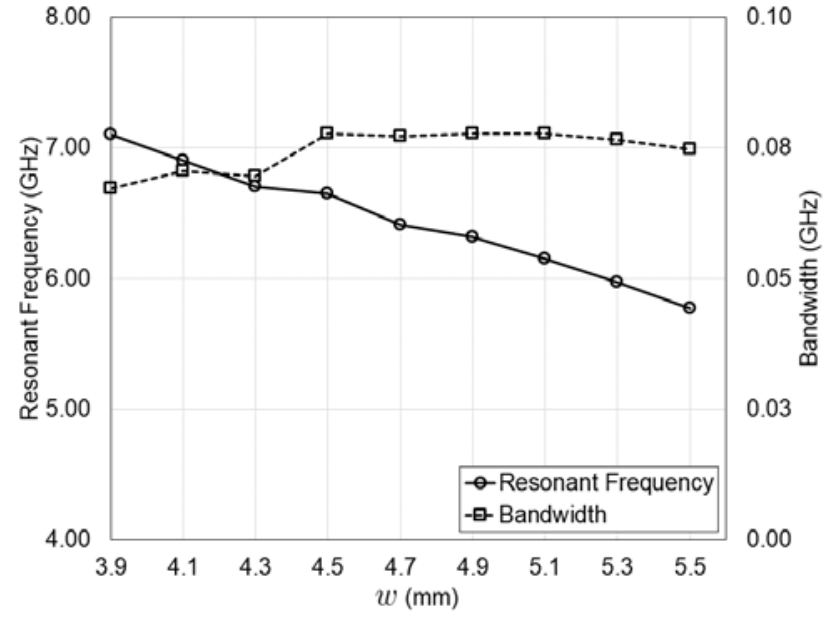

Fig. 9 Values of resonance frequency and bandwidth due to changes in patch length.

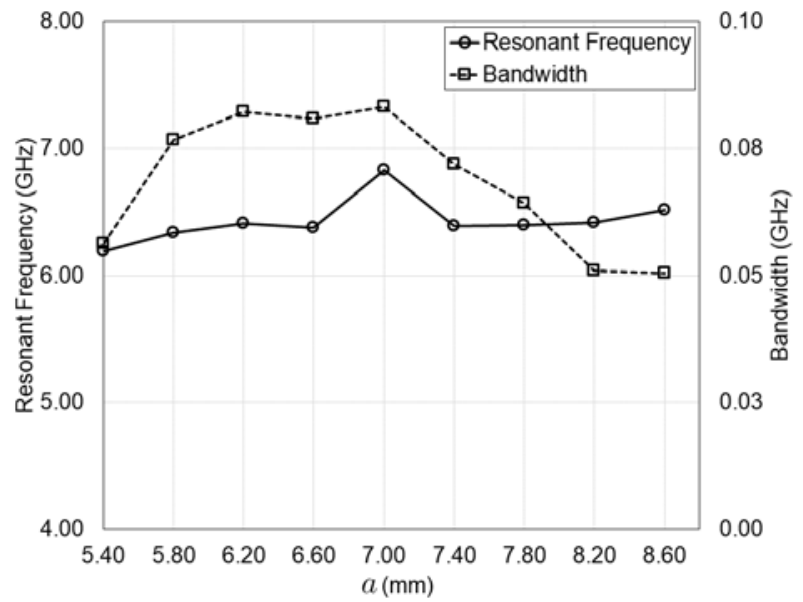

Fig. 10 Values of resonance frequency and bandwidth due to the changes in the ground plane side.

is increased. The bandwidth magnitude increases when the resonator side length is changed from $3.9 \mathrm{~mm}$ to $4.1 \mathrm{~mm}$, which is $0.003 \mathrm{GHz}$. When the resonator side length is changed from $4.1 \mathrm{~mm}$ to $4.3 \mathrm{~mm}$, the bandwidth is relatively stable. Then, when the resonator side length is changed from $4.3 \mathrm{~mm}$ to 4.5 $\mathrm{mm}$, the most significant increase in bandwidth occurs, which is $0.008 \mathrm{GHz}$, and it returns stable when the resonator side length is changed to $4.9 \mathrm{~mm}$. When the resonator side length is $4.9 \mathrm{~mm}$, the bandwidth reaches the maximum point, which is $0.078 \mathrm{GHz}$, and decreases when the resonator side length value is increased one more time.

Fig. 10 shows the effect of modification in the ground plane side length to changes in the resonant frequency values and the bandwidth magnitude. From the nine samples taken, the resonant frequency values change variously starting from increasing, decreasing, and stable. The increase in the resonant frequency values occur when the ground plane side length is modified from $5.4 \mathrm{~mm}$ to $5.8 \mathrm{~mm}$, i.e. from $6.19 \mathrm{GHz}$ to 6.34 $\mathrm{GHz}$, and when the length ground plane side length is modified from $5.8 \mathrm{~mm}$ to $6.2 \mathrm{~mm}$, the resonant frequency has increased to $6.41 \mathrm{GHz}$. When the ground plane side length is modified 
from $6.6 \mathrm{~mm}$ to $7.0 \mathrm{~mm}$, the resonant frequency reaches its maximum point when the value reaches $6.83 \mathrm{GHz}$, and then decreases when the ground plane side length is increased one more time. Modifications in the ground plane side length also significantly influence the bandwidth magnitude. When the ground plane side length is increased from $5.4 \mathrm{~mm}$ to $7 \mathrm{~mm}$, the bandwidth increases and reaches its maximum point, which is $0.083 \mathrm{GHz}$. If the ground plane side length is increased one more time, the bandwidth decreases.

\section{CONCLUSIONS}

From the research of square electromagnetic wave absorber, square resonator, and broadside SRR on C-Band with a resonance frequency of $6.41 \mathrm{GHz}$, it could be concluded that the three shapes were able work well as electromagnetic wave absorbers with an average absorption rate of 99.986\%. Square shape produced the highest absorption rate, which reached $100 \%$. However, its dimension was quite large, which was $17.84 \mathrm{~mm}$. The square resonator had an absorption rate of 99.97\% with its dimension smaller than the square shape's dimension, which was $16.25 \mathrm{~mm}$. While the broadside SRR shape had an absorption rate of $99.99 \%$ and had the smallest dimension, which was $7 \mathrm{~mm}$. From the broadside SRR characterization, the resonant frequency and bandwidth values were greatly affected by the gap length variable. If the gap length value was increased, the greater the resonant frequency and bandwidth values were.

\section{REFERENCES}

[1] L.O. Nur, A. Munir, Sugihartono, and A. Kurniawan, "Perancangan dan Fabrikasi Penyerap Gelombang Elektromagnetik Patch Segi Enam Berbasis Surface Textured,” Jurnal Penelitian dan Pengembangan Telekomunikasi, Kendali, Komputer, Elektrik, dan Elektronika, Vol. 1, No. 1, pp. 40-45, 2016.

[2] L.O. Nur and A. Munir, "Thin EM Wave Absorber Composed of Octagonal Patch Array and Its Characteristic Measurement," 2015 3rd International Conference on Information and Communication Technology (ICoICT), 2015, pp. 604-607.

[3] J. Tak and J. Choi, "A Wearable Metamaterial Microwave Absorber," IEEE Antennas and Wireless Propagation Letters, Vol. 16, pp. 784-787, 2017.
[4] H.B. Baskey and M.J. Akhtar, "A Dual-band Hexagonal Ring Based Polarization-insensitive Metamaterial Absorber," IEEE MTT-S International Microwave and RF Conference, 2013, pp. 1-4.

[5] Y. Ze and L. Gui-Zen, "An Ultra-thin and Broadband Absorber Using Slotted Metal Loop with Multi Layers,” Optik, Vol. 127, No. 1, pp. 387389, 2016.

[6] N. Engheta and R.O. Ziolkowski, Metamaterials Physics and Engineering Explorations, Ottawa, Canada: John Wiley \& Sons, Inc., 2006.

[7] D. Chaurasiya, S. Ghosh, and K.V. Srivastava, "Dual Band Polarizationinsensitive Wide Angle Metamaterial Absorber for Radar Application," 2014 44th European Microwave Conference, 2014, pp. 885-888.

[8] K. Srivastava, A. Kumar, A.K. Verma, and Q. Zhang, "Quad-band Polarization Independent Ultra-thin Microwave Absorber Using Metamaterial," 2015 39th National Systems Conference (NSC), 2015, pp. 1-4.

[9] J. Tak, Y. Jin, and J. Choi, "A Dual-band Metamaterial Microwave Absorber," Microw. Opt. Technol. Lett., Vol. 58, No. 9, pp. 2052-2057, 2016.

[10] A.K. Singh, M.P. Abegaonkar, and S.K. Koul, "Penta Band Polarization Insensitive Metamaterial Absorber for EMI/EMC Reduction and Defense Applications," 2017 IEEE MTT-S International Microwave and RF Conference (IMaRC), 2017, pp. 1-5.

[11] P.Z. Peebles, Radar Principles, New York, USA: John Wiley and Sons, Inc., 1998.

[12] G. Maral and M. Bousquet, Satellite Comunications Systems, New York, USA: John Wiley and Sons, Inc., 2010.

[13] W. Chen and M. Liang, "LTE/5G C-band MIMO Antennas for Laptop Computers," 2018 International Symposium on Antennas and Propagation (ISAP), 2018, pp. 1-2.

[14] K. Schubert, W. Jens, and F. Schwartau, "Design of an Bi-static C-band Radar for Characterisation of Wind Turbine Plants," Asia-Pacific International Symposium on Electromagnetic Compatibility (APEMC), 2017, pp. 7-9.

[15] L.O. Nur, A. Kurniawan, Sugihartono, and A. Munir, “Theoretical Analysis of Resonant Frequency for AMC-based Absorber Composed of Square Patch Array,” International Journal on Electrical Engineering and Informatics, Vol. 7, No. 2, pp. 284-296, 2015.

[16] T.T. Nguyen and S. Lim, "Bandwidth Enhancement of Metamaterial Absorber Using Double Resonance," 2017 IEEE Asia Pacific Microwave Conference (APMC), Kuala Lumpur, 2017, pp. 380-382. 